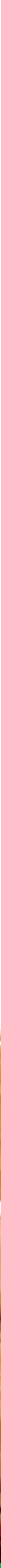

The food systems approach: sustainable solutions for a sufficient supply of healthy food 



\section{The food systems approach: sustainable solutions for a sufficient supply of healthy food}

Siemen van Berkum, Just Dengerink and Ruerd Ruben

This study was carried out by Wageningen Economic Research and was commissioned and financed by the Dutch Ministry of Agriculture, Nature and Food Quality

Wageningen Economic Research

Wageningen, June 2018

MEMORANDUM

2018-064 
Siemen van Berkum, Just Dengerink and Ruerd Ruben, 2018. The food systems approach: sustainable solutions for a sufficient supply of healthy food. Wageningen, Wageningen Economic Research, Memorandum 2018-064. 32 pp.; 9 fig.; 0 tab.; 39 ref.

A food systems approach (FSA) is a useful interdisciplinary conceptual framework for research and policy aimed at sustainable solutions for the sufficient supply of healthy food. An FSA analyses the relationships between the different parts of the food system and the outcomes of activities within the system in socio-economic and environmental/climate terms. Feedback loops are a distinguishing factor in systems thinking: they occur between parts of the food chain (production, processing, distribution and consumption) and from the socio-economic and environmental outcomes of food production and consumption (such as food security and soil depletion) back to that production and consumption. The FSA sheds light on non-linear processes in the food system, and on possible trade-offs between policy objectives. Systems thinking also broadens the perspective when seeking solutions for the root causes of problems such as poverty, malnutrition and climate change. The framework offers at least three benefits. First, it provides a checklist of topics that should at the very least be addressed when it comes to improving food security, certainly in relation to other policy objectives. Second, FSA helps to map the impact of environmental and climate changes on food security by pointing to the various vulnerabilities of the food system. In that sense the approach can contribute to the search for possibilities for strengthening the system's resilience to climate changes. Third, it helps to determine the most limiting factors for achieving food security, and hence identify effective interventions aimed at improving food security.

Key words: food systems approach, conceptual, framework, healthy, food, sustainability

This report can be downloaded for free at https://doi.org/10.18174/451505 or at www. wur.eu/economic-research (under Wageningen Economic Research publications).

(C) 2018 Wageningen Economic Research

P.O. Box 29703, 2502 LS The Hague, The Netherlands, T +31 (0)7033583 30,

E communications.ssg@wur.nl, http://www.wur.eu/economic-research. Wageningen Economic Research is part of Wageningen University \& Research.

\section{(cc) BY-NC}

For its reports, Wageningen Economic Research utilises a Creative Commons Attributions 3.0 Netherlands license.

(C) Wageningen Economic Research, part of Stichting Wageningen Research, 2018

The user may reproduce, distribute and share this work and make derivative works from it. Material by third parties which is used in the work and which are subject to intellectual property rights may not be used without prior permission from the relevant third party. The user must attribute the work by stating the name indicated by the author or licensor but may not do this in such a way as to create the impression that the author/licensor endorses the use of the work or the work of the user. The user may not use the work for commercial purposes.

Wageningen Economic Research accepts no liability for any damage resulting from the use of the results of this study or the application of the advice contained in it.

Wageningen Economic Research is ISO 9001: 2008 certified.

Wageningen Economic Research Memorandum 2018-064 | Project code 2282500215

Cover photo: Shutterstock 


\section{Contents}

1

The food systems approach as a broad interdisciplinary conceptual framework

2.1 Definition

2.2 Contribution of the food systems approach

3.1 Increasing the supply

3.2 Of safe, healthy food

3.3 Within environmental limits 9

3.4 In an inclusive way $\quad 9$

$\begin{array}{lll}4.1 & \text { Food system activities } & 11\end{array}$

$\begin{array}{lll}4.2 & \text { Food system outcomes } & 12\end{array}$

$\begin{array}{lll}4.3 & \text { Environmental drivers of the food system } & 13\end{array}$

$\begin{array}{lll}4.4 & \text { Socio-economic drivers of the food system } & 15\end{array}$

Using the food systems approach to look for sustainable solutions for a sufficient supply of healthy food: examples

5.1 Increasing the food supply: more production, less loss and less waste

5.2 Malnutrition: influencing consumer behaviour and the production of healthy food

5.3 Climate change: feedback involving food system activities 20

5.4 Poverty and productivity: escaping the poverty trap 22

$\begin{array}{lll}6.1 & \text { From activities to outcomes } & 23\end{array}$

$\begin{array}{lll}6.2 & \text { Interdependence } & 23\end{array}$

$\begin{array}{lll}6.3 & \text { Tipping points } & 24\end{array}$

6.4 Action perspective: prioritising interventions using problem analyses based on a food systems approach 



\section{$1 \quad$ Introduction}

The European Agriculture and Fisheries Policies and Food Security Department (ELVV) of the Dutch Ministry of Economic Affairs has identified a need to explore the usefulness of the food systems approach (FSA) in shaping the Ministry's contribution to Dutch policy on food security, aid, trade and investment policy. That need is fuelled by the following:

- The food system is increasingly being used internationally as a useful analytical framework for the integrated consideration of interests relating to food and for introducing a policy focus on public health and the ecological sustainability and robustness of food production and consumption. See for example UNEP (2016), Global Panel (2016) and HLPE (2017).

- Dutch policy on food security centres on three themes: 1 . eliminating hunger and malnutrition, 2. inclusive and sustainable growth, and 3. environmentally sustainable food systems (Kamerbrief, 2014). The concept of 'food systems' can be useful for showing the relationship between these themes.

- The Directorate Inclusive Green Grwoth (IGG) at the Ministry of Foreign Affairs employ what is called 'nexus thinking'. This involves linking (adopting an integrated approach to) food security, climate, energy, water and biodiversity challenges. The food system plays a major role in all these challenges and the systems approach immediately highlights who the relevant players are.

- The top sectors Agri \& Food and Made in Holland Horticulture and Starting Materials have announced in their strategy that they are wanting to work on systems solutions in emerging and developing countries.

- The international agri-business cluster of ELVV-DG Agriculture and Nature (DGA\&N) at the Ministry of Economic Affairs is working with the Sustainable Economic Development (DDE) and the Inclusive Green Growth (IGG) departments at the Ministry of Foreign Affairs and the Netherlands Enterprise Agency (RVO) on guidelines for sector development and wishes to incorporate these into an FSA.

- Food systems are subject to rapid change (especially in emerging countries, but in developing countries too) in response to growing prosperity and urbanisation, in combination with increases in scale, globalisation and the consolidation of players in food systems.

- The balanced inclusion of Sustainable Development Goals (SDGs) in policy and implementation also calls for an integrated framework.

- The Netherlands Environmental Assessment Agency (PLB) has argued in regular interdepartmental DG meetings that policy should be based more on system levels (food, transport/logistics, energy and urban systems) and the interactions between them. The suggestion was very well received.

The aim of this paper is twofold: to explain the term 'food systems approach' in greater detail, and to show how a food systems conceptual framework (one that is firmly imbedded in the international literature in this field) can be useful in developing an integrated international policy on food security, nutritional security and international agri-business.

Food systems thinking gained increasing traction following the sharp price rises for agricultural and other commodities in 2008/09, which once again put food security (or rather, food insecurity) high on the policy agenda. In addition to expanding food production, improved access to food became an important component in the thinking about food security. At the same time, the limitations of natural conditions for a growth in agricultural production became increasingly clear, especially in relation to anticipated climate changes. It was also clear that an increase in food production alone would not improve food security but that nutritional value is important when it comes to combatting malnutrition (and obesity). The research community and policymakers were encouraged to look more broadly than at agricultural production alone in order to enhance food security for a growing world population. Since then, many reports and scientific articles have appeared that use the food systems approach as a framework for understanding changes in food systems in relation to food security and climate change. This also makes it a useful approach for designing transformative action at the interface between science and policy (see for example Fresco et al., 2017). 


\section{The food systems approach as a broad interdisciplinary conceptual framework}

\subsection{Definition}

Food systems comprise all the processes associated with food production and food utilisation: growing, harvesting, packing, processing, transporting, marketing, consuming and disposing of food remains (including fish). All these activities require inputs and result in products and/or services, income and access to food, as well as environmental impacts. A food system operates in and is influenced by social, political, cultural, technological, economic and natural environments (HLPE, 2014; UNEP, 2016; Global Panel 2016; HLPE, 2017). ${ }^{1}$

Because the nature and operation of food systems is determined by many factors, the FSA can be studied from the perspective of a range of disciplines (including anthropology, sociology, economics and geography). The literature on the subject is not always entirely clear and complete in terms of the attention paid to all the processes that are part of the food system. Whereas HLPE (2014) places a good deal of emphasis on reducing food loss and waste in the food system and UNEP (2016) focuses on the food system's interaction with natural resources and the environment, the Global Panel (2016) and HLPE (2017) emphasise the role of the consumer: it is consumers who determine what the system produces. According to the latter two publications, food culture (values, convictions and social norms regarding food) plays a key role in what people eat. Incomes and other socio-economic characteristics in a society also determine to a significant degree the choice of food, as does, for example, knowledge of the relationship between nutrition and health (Global Panel, 2016:82-83). In addition to sufficient quantities of food, food systems should in particular produce healthy food ('healthy diets') and the Global Panel report suggests how interventions in food systems can bring that goal a step closer.

The food systems approach describes the different elements in our food system and the relationships between them. It looks on the one hand at all the activities relating to the production, processing, distribution and utilisation of food, and on the other hand at the outcomes of these activities in terms of food security (including nutrition), socio-economics (income, employment) and the environment (biodiversity, climate). In this paper we do not opt for a single definition of food systems but we attempt to do justice to the different definitions by emphasising the breadth of the FSA and to show, using examples from different perspectives (in other words, the activity leading to better access to healthy food, or the main driver of change leading to a response in the food production system), how it can be applied in practice. ${ }^{2}$

A defining feature of systems thinking is that it views the behaviour of a system as an interplay of interacting subsystems, in which feedback plays a key role, rather than as a simple chain of causeeffect relationships. This also distinguishes systems thinking from other approaches such as farming systems, sector or chain approaches, in which interventions are often designed to make optimum use of the means of production (natural resources, labour, capital). This usually involves applying technological innovations at the level of family businesses, sectors and/or chains, with the focus on raising productivity and profitability. Although those approaches also analyse the impact of

1 It is difficult to decide on a precise demarcation of food systems. With respect to nutrition, for example, should we also include health care? We regard the functions of food production, trade and consumption as central, along with the actors and rules/institutions that are directly involved. Interactions with the environment (macroeconomics, the energy market, labour market, etc.) are also part of it. These are non-agricultural or food policy fields, which are relevant inasmuch as they can have an impact on food production, trade and consumption, also regarding efforts towards policy coherence. For a key work on systems thinking, see Boulding (1956), who presents a hierarchy of systems and distinguishes levels of system complexity within them.

2 In addition to HLPE (2017), UNEP (2016) and Global Panel (2016), for applications in slightly older literature, see among others: Ingram and Brklacich 2002; Maxwell and Slater, 2003; Ericksen, 2007; Ingram, 2011. 
interventions on the market (prices, incomes) and environment ( $\mathrm{CO}_{2}$ emissions), and the depletion of natural resources (such as erosion or water shortage), they tend to pay insufficient attention to feedback from the socio-economic system and/or ecosystem to the farm, sector or chain. Food systems thinking steps back as it were from the place where the intervention occurs, thereby providing an opportunity when analysing the outcomes of policy interventions to include feedback from outcomes outside the activities that relate directly to food production and consumption. This also makes an FSA a useful perspective in the literature on the resilience (robustness) of the food production system, which is about the capacity of the system to absorb shocks, such as an animal disease crisis or trade boycott. Climate change is an example of a 'shock' with a long-term dimension. The sustainable use of natural resources in relation to the growing need for food is a key focus in the literature on resilience (e.g. Ge et al., 2017; Suweis, 2016; Weelher and Von Braun, 2013) and ways are being sought to make food production less vulnerable to these shocks. The solution approaches emphasised in this literature include the need for climate-smart agriculture (a combination of increasing agricultural productivity and reducing greenhouse gas emissions), supplemented by policy aimed at trade, supplies and nutrition and social policy options. This is because the availability of food does not guarantee that people can also access it. Integrated system solutions are advocated, in which an FSA - because of its holistic nature - is a more appropriate analytical framework than an approach that focuses solely on the production component (Ge et al., 2017).

In the ecology and economic discipline, the term resilience is used to indicate the ability to cope with perturbations and the rate and speed of recovery after their occurrence. Resilience thinking has been applied to a wide variety of social-ecological systems, also in studies dealing with the behaviour of agricultural systems facing various kinds of perturbations, most frequently as the ability of agricultural systems to preserve their intrinsic functions through flexibility. In these cases, resilience is mainly used to discuss the factors that build the ability of agricultural systems to respond to changes, to reorganise their structure, to anticipate future changes and to take advantage of new opportunities (for further reading about the concept of 'food system resilience' see Folke et al., 2010; Urruty et al., 2015 and Tendall et al., 2015).

\subsection{Contribution of the food systems approach}

The FSA provides a framework showing where the main interactions and feedback between the subsystems occur (UNEP, 2016). This produces a number of useful insights:

- It maps out opportunities for a more efficient use of natural resources.

- It highlights the important role of the food system's socio-economic context.

- It shows the implications of the food system for health and malnutrition.

- It helps to shed light on the trade-offs between different intervention strategies.

- It sheds light on non-linear processes and feedback loops in the food system.

Thus, unlike a focus on a value chain or farming system, the FSA looks at the interactions within the food system and its socio-economic and biophysical environment. It also highlights policy pathways that do not intervene in the value chain itself, but in the context of the food production system. These include a tax on 'unhealthy' nutrition or promoting investments in the infrastructure needed for the production, storage and transport of - usually perishable - vegetables and fruit (regarded as the most nutritious foods). And by providing a broader view of the impact of different intervention strategies, it helps in the weighing-up of particular policy choices. The FSA thus provides insights into opportunities for effective entry points for longer-term policy.

Insights from the FSA can be helpful in tackling the challenges of future food supply. Section 3 of this paper summarises these global food challenges, which are centred on food production, nutrition, the environment and poverty. The food system and its various subsystems are briefly described in Section 4. In Section 5, examples are presented to illustrate how food systems thinking can be used to assess the impact of interventions aimed at solutions for one of the challenges outlined. Section 6 briefly summarises the contribution of food systems thinking to the challenges of the future and makes several suggestions for policy implications. 


\section{$3 \quad$ Challenges of future food supply}

\subsection{Increasing the supply}

In the next three decades the world's population will increase, rising to 9 billion in 2050, with the biggest growth occurring in areas that are already facing food insecurity. After several years of decline, the number of people suffering from chronic hunger is once again on the rise, reaching more than 800 million in 2016 , or $11 \%$ of the current world population (FAO, 2017a). Viewed in this light, the SDG 2 target (zero hunger in 2030) is very ambitious.

The FAO (2017a) estimates that in a business-as-usual scenario food production will have to increase by $50 \%$ in order to feed the growing world population in 2050 . At the same time, the quantity of available agricultural land is declining through soil degradation, and resources such as water and energy are becoming increasingly scarce. The growth in yield per hectare has also declined in recent decades. The current growth in grain productivity is half of what is needed to achieve the required doubling of production (WWF, 2016).

And yet a greater supply of food does not depend on productivity growth alone. At present a substantial proportion (about 30 to $40 \%$ ) of the total amount of food that is produced is lost in the various steps of the value chain (FAO, 2013). Also, large areas of land suitable for agriculture are being used for the production of biofuels. By reducing waste and/or recycling minerals and food remains as animal feed or compost (circularity), or switching to alternative energy sources (other than biofuels), we could increase the food supply without having to put more land into production or to use land more intensively. In addition, animal production requires more energy, land and water than plant production (e.g. Shepon et al., 2016). A reduction in meat consumption would reduce the demand for animal feed, which would enable the increased production of plant food crops, thereby making more food available overall. Policy aimed at reducing loss, recycling food remains or promoting plant consumption patterns can make a significant contribution to SDG 12 (responsible consumption and production).

\subsection{Of safe, healthy food}

As well as food availability, dietary composition also entails sizeable challenges. In total, 2 billion people suffer from a shortage of micronutrients. This mainly affects children in the first few years of life; worldwide a total of 159 million children younger than 5 suffer from stunted growth and 50 million children from wasting (UNEP, 2016), while on average $19 \%$ of the people in Sub-Saharan Africa and $22 \%$ of those in the least developed countries are undernourished (World Bank, 2016).

In addition, more than 2 billion people are either overweight or obese (including 41 million children younger than 5). This figure is expected to be 3.3 billion in 2030. Increasingly, the world's population has begun eating a diet that is too sweet, too salty and contains too much fat. Chronic diet-related diseases such as diabetes have become increasingly common, especially in low and middle-income countries. And poor nutrition exacerbates the health impacts of diseases such as HIV/AIDS, malaria and measles. Healthy food would therefore make a significant contribution to SDG 3 (good health and wellbeing).

A major challenge for the food system is to ensure the production and consumption of sufficiently varied diets containing the right micronutrients (vitamins and minerals). Better health among the working population contributes to a healthy economy. The estimated impact of malnutrition on GDP is $11 \%$ per annum (Global Panel, 2016). The Global Nutrition Report 2016 states that investing 1 dollar in healthy food will yield 16 dollars for the economy (the sum of higher productivity in the labour market, lower absenteeism and lower health costs). 


\subsection{Within environmental limits}

Natural resources such as soil and water form the foundation for food production; sustainable use of these resources is essential in order for the food system to function well (UNEP, 2016). The global food system is approaching its environmental limits. The food system is the dominant cause of deforestation and shrinking biodiversity and is a major user of scarce water resources. In the meantime, the quantity of fertile land available for agriculture is on the decline, with $33 \%$ of all soils subject to degradation (WWF, 2016).

Research shows that the food system is responsible for $19-29 \%$ of anthropogenic greenhouse gas emissions. Agricultural production, including its indirect effects through changing land use, accounts for $80-86 \%$ of this, and other activities in the food system such as processing and transport account for the remainder. Conversely, the food system is to a large degree dependent on environmental conditions. Studies show that climate change will have a significant impact on production, food prices and farmer incomes (Vermeulen et al., 2012; OECD, 2015). Mitigation measures (e.g. increase energy efficicency, or carbon tax and emissions markets) are therefore important strategies for reducing greenhouse gas emissions, whereby the agriculture and food-processing sectors can also contribute to SDG 13 (Climate action) and SDG 15 (Biodiversity).

A drastic reduction in the environmental impact of the agricultural system calls for a different way of managing production chains and influencing consumer behaviour. The current food system is threatening the functioning of existing ecosystems to such an extent that this can lead to a sharp drop in productivity and in total agricultural yields (Lobell et al., 2011). To lessen that threat, we need to clearly analyse the impact of food production on the ecosystem, and this includes feedback from the ecosystem (and disruptions in that system) to the agricultural sector. An FSA provides a suitable process for this.

\subsection{In an inclusive way}

Agri-food is the world's largest economic sector. More than 2 billion people work in the food system, with half of the world's working population active in agriculture. In emerging and developing countries in particular, agriculture continues to be an important livelihood (and therefore also a social safety net). However, the food system fails to provide most of these people with an adequate income: three-quarters of all farmers live in poverty (New Foresight, 2017). Poverty is the biggest threat to and the major cause of food insecurity (WWF, 2016). SDG 1 (End poverty) has set a target of ending extreme poverty (<US\$ 1.25 per day) by 2030 and reducing the number of people living in poverty by half. According to the FAO (2017b), investing in agricultural and rural development is the key to eliminating hunger and poverty but this does have to generate economic growth that the poorest of the poor can also benefit from. This will not simply happen of its own accord: in order to promote inclusive growth, countries may want to develop economic and social policy and programmes that specifically target the poorest groups.

There is a direct correlation between the living conditions of farmers and agricultural workers and the functioning of the food system. When farmers have sufficient resources to be able to access a varied diet, training and basic healthcare, this results in a higher labour productivity. Moreover, a farmer with sufficient earnings can make the transition more easily to a more sustainable form of production (WWF, 2016). These opportunities are limited, however, if much of the market power in food chains is concentrated in the hands of a small number of traders and retailers who can set the conditions for price and quality (whether or not driven by the globalisation process). Farmers risk to be excluded from the value chain if they are not able to meet the conditions of the most influential players in that chain. At the same time, especially in many developing countries, there is a tension between consumers in urban areas (the urban poor), for whom affordable food is vital, and the interests of farmers (the rural poor), who want high (or higher) prices for their products in order to climb out of poverty. The question is how the food system can be organised in a way that satisfies both sets of interests. 


\section{$4 \quad$ Mapping the food system}

As stated earlier, the FSA looks not only at the activities of the food system, but also at outcomes in the form of food security, and socio-economic and environmental indicators. In this section we will describe the parts of the food system and how they interrelate, based on literature about the FSA (Global Panel, 2016; UNEP, 2016; Ingram, 2011; Ericksen, 2007).

The food system is made up of a number of activities (see Figure 1) whose primary aim is to increase food security. Activities in the food system encompass not only activities within the value chain, but also service organisations (business services) and the 'enabling environment' (e.g. food safety regulations). A number of factors that influence activities at the consumer level are also included: the food environment and the characteristics of (individual) consumers, both of which determine the consumer's relationship to food.

These food system activities contribute to outcomes at the socio-economic level (such as income and work), and in the areas of the environment and food security - defined as the use of, access to and availability of food. These three outcomes interact with one another. For example, certain socioeconomic outcomes such as income can increase food availability, and better food utilisation (e.g. reducing food waste) could have a positive environmental impact because it can lead to less intensive land use. On the other hand, there are also trade-offs between environmental, socio-economic and food security outcomes (Ericksen, 2007). Thus an increase in food production can put more pressure on the environment and certain choices concerning food access can lead to unequal socio-economic outcomes. Lastly, socio-economic and environmental conditions in turn affect the functioning of the food system. Figure 1 presents the components of the socio-economic and environmental drivers ${ }^{3}$ and uses arrows to show the feedback between the system components.

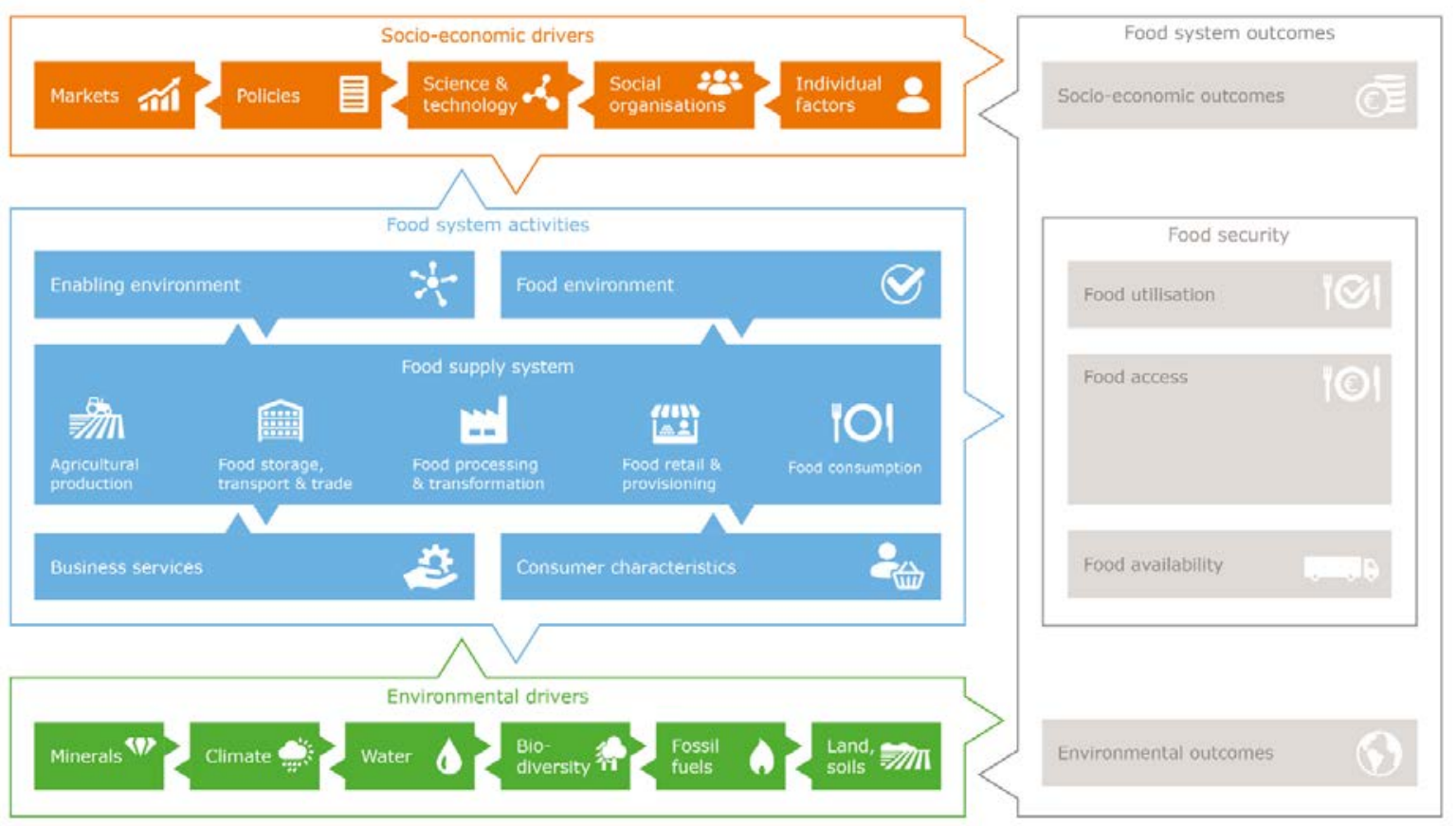

Figure 1 A way of mapping the relationships of the food system to its drivers

3 Drivers of change are factors that are regarded as exogenous to the change process. Thus population growth, economic/macro-economic growth and urbanisation are key socio-economic drivers of changes in the food system. Ecological or environmental drivers are natural factors or factors affected by human intervention which directly or indirectly bring about a change in the ecosystem. Climate change, soil nutrients and land use are major environmental drivers. 


\subsection{Food system activities}

The food system activities, which are shown in more detail in Figure 2, consist of five components: the food supply system (the value chain), the enabling environment, business services, the food environment and consumer characteristics. These components are explained briefly below.

The value chain is at the heart of the food supply system: value is added in each step of the chain, from production, storage and transport, and processing, to retail and consumption. Agricultural production has traditionally been at the centre of the food supply system, given that $50 \%$ of the world's labour force works in that sector (ILO, 2015). In terms of added value, the emphasis of production chain activities is increasingly shifting to transport, processing or retail.

The food supply system is imbedded in an enabling environment that creates the conditions in which the system functions. Transport, regulation, institutions and research infrastructure are part of this environment.

Business services, while not at the heart of the value chain, provide services and goods to the actors in the chain. This can involve training, agricultural inputs, technical support or financial services.

Just as the enabling environment and business services support the production, transport and processing industry, there are also two system support components at the retail and consumer level: the food environment and consumer characteristics.

The food environment comprises a number of determining environmental factors, such as the extent to which a product is advertised or the information on labels or quality seals determines the consumer's relationship to that product.

At the bottom of Figure 2 are the characteristics of consumers, who - through their knowledge, available time, resources (purchasing power), age, sex, culture, religion, etc. - develop certain preferences that influence their food choices.

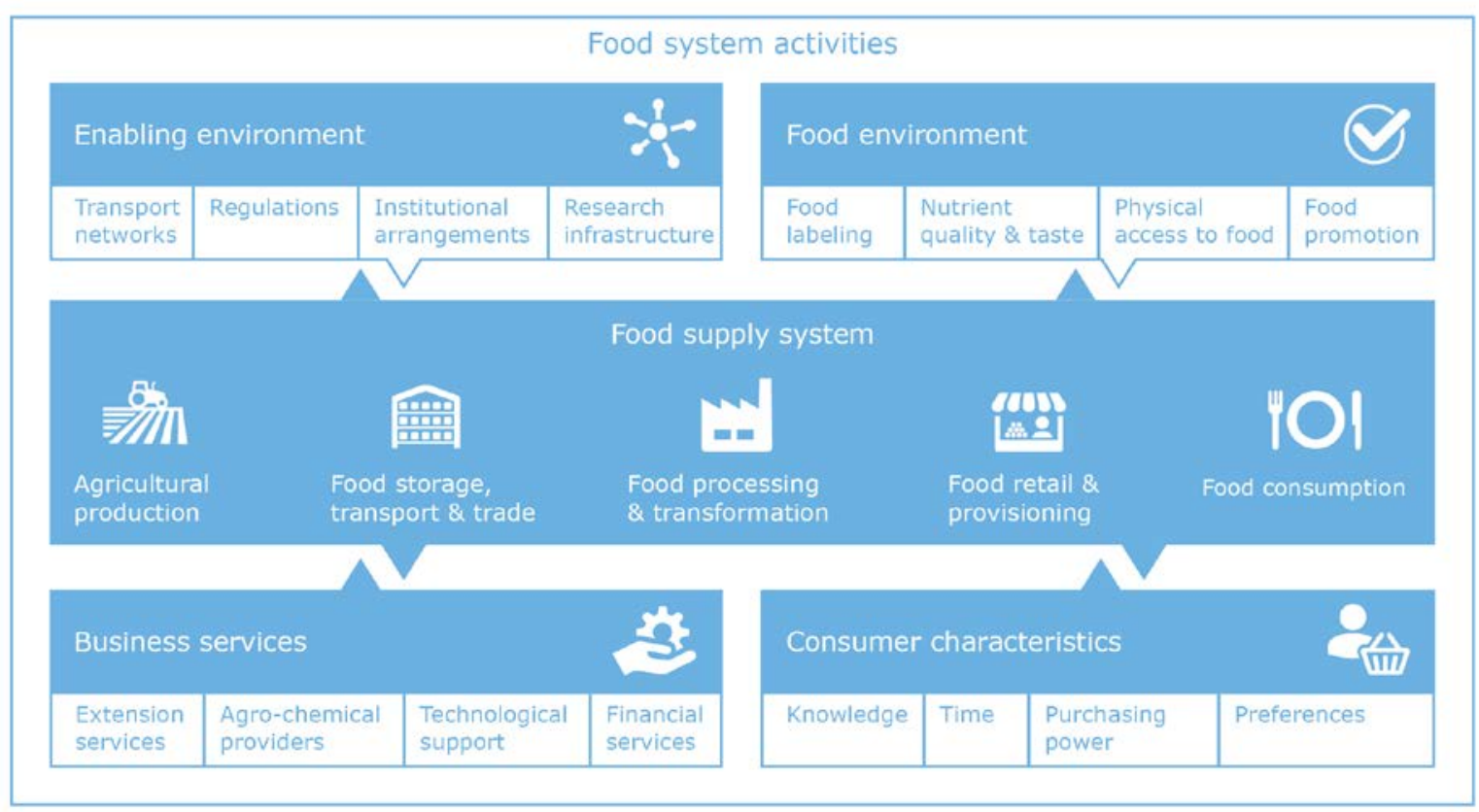

Figure 2 Food system activities 


\subsection{Food system outcomes}

We distinguish three types of food system outcomes: socio-economic, environmental, and outcomes relating to food security. Figure 3 shows the main indicators for these outcomes (see Eriksen, 2007; Ingram, 2011; UNEP, 2016 for a detailed description of the indicators shown in the figure).

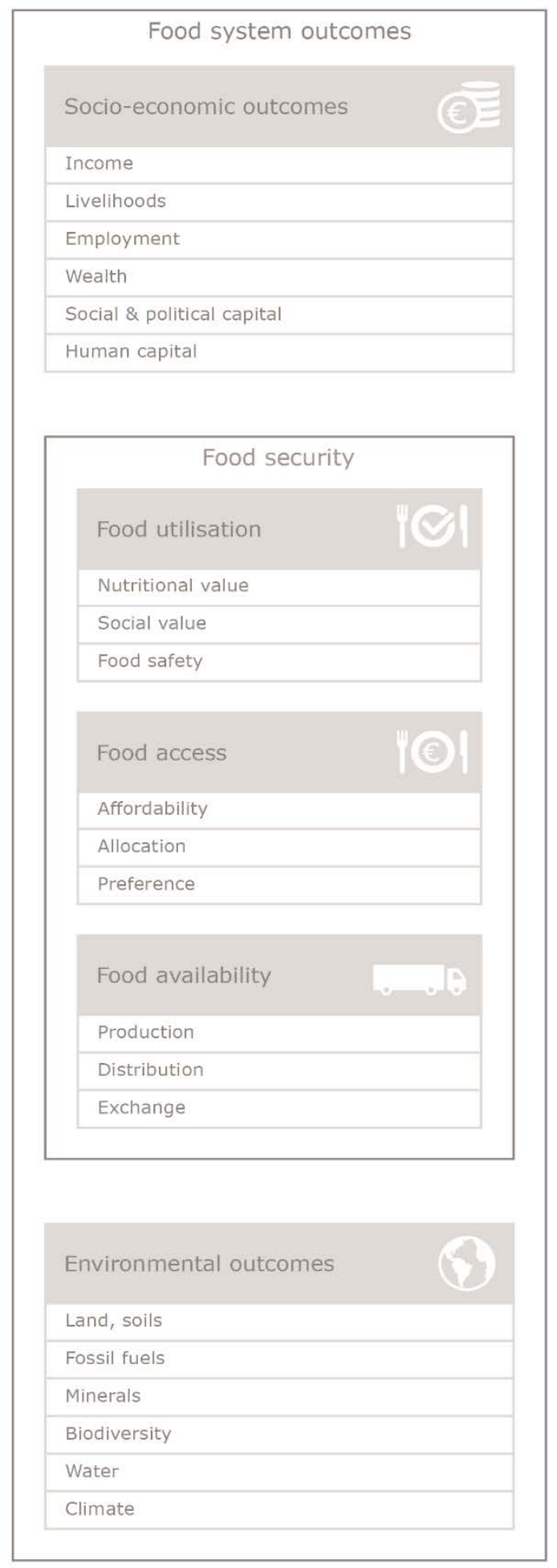

Figure 3 Food system outcomes

The socio-economic outcomes of the food system involve things like the incomes and living conditions of farmers' families and other actors in the food system, as well as the employment and wealth that 
these activities generate. They also involve the social, political and human capital generated by these activities.

Food security is often defined in the literature as a combination of food utilisation, food access and food availability. ${ }^{4}$ Utilisation entails the nutritional value, social value and safety of the product; access involves food affordability, allocation and preferences; and availability is about food production, distribution and exchange.

Lastly, there are the environmental outcomes of the food system - namely, its impact on natural resources and the biophysical drivers of the food system.

Box 1: Definition of food security (FAO, 1996)

\section{Food availability}

- Production = how much and which types of food are available through local production.

- Distribution = how food is made available (physically moved), in what form, when and to whom.

- Exchange = how much of the available food is obtained through exchange mechanisms such as barter, trade, purchase, or loans.

\section{Access to food}

- Affordability = the purchasing power of households or communities relative to the price of food.

- Allocation = the economic, social and political mechanisms governing when, where and how food can be accessed by consumers.

- Preference $=$ social, religious or cultural norms and values that influence consumer demand for certain types of food.

\section{Food Utilisation}

- Nutritional value $=$ how much of the daily requirements of calories, vitamins, protein, and micronutrients are provided by the food people consume.

- Social value $=$ the social, religious and cultural functions and benefits food provides.

- Food safety = toxic contamination introduced during producing, processing and packaging, distribution or marketing food; and food-borne diseases such as salmonella and CJD.

\subsection{Environmental drivers of the food system}

The environmental drivers indicate the biophysical context in which the food system operates. These consist of five interacting components (see Figure 4 on the next page):

1. The availability of land for agriculture and livestock farming, and related to this, the quality of soils. Intensive agricultural methods can put pressure on soil quality.

2. The use of fossil fuels in agricultural machinery and equipment, refrigeration, storage, processing and transport of food. Fuels used for the production of fertilisers and pesticides are also included in this category. A side effect of burning these fuels is the emission of additional greenhouse gases such as carbon dioxide $\left(\mathrm{CO}_{2}\right)$, which contributes to climate change.

3. The use of minerals/microminerals, such as NPK and lime, to enrich soils and various metals such as steel, tin and bauxite for the manufacture of packaging, infrastructure and cookware. The growing scarcity of some minerals poses a challenge for the agricultural system.

4. Biodiversity (the variety of plant and animal life) provides different services to the food system activities, such as biomass and firewood, as well as animals for domestication, microbes that guarantee soil quality and a diversity of plant and animal species that enable pollination. The expansion of the agricultural area and climate change pose a direct threat to biodiversity.

5. Water, as an important source of life. This involves not only the availability of water for irrigation, but also high-quality drinking water for cooking, and water for washing.

\footnotetext{
4 Stability is a fourth dimension of food security; it shows how the other three cornerstones of food security (availability, access, utilisation) are safeguarded over time.
} 
The interaction between environmental drivers and food system activities occurs mainly at the level of agricultural production (arable farming, horticulture, livestock farming, fishing), and to a lesser extent at the level of other activities in the value chain, such as processing, distribution, domestic and international trade and consumption. However, activities throughout the value chain can influence the use of natural resources in the primary part of the chain, and solutions aimed at the more efficient use of resources can arise from changes in all parts of the chain.

There are also strong interrelationships between the environmental drivers: the quality of soils depends on the quantity of water and minerals; climate change has put pressure on water availability in many regions; and biodiversity is declining worldwide. However, pressures on water availability or biodiversity impacts of climate change will be different among regions, depending on the starting point regarding natural conditions and the impact of social interactions or behaviour on natural resources. Indeed, the biophysical base of food systems can differ regionally, as soil quality, water availability, temperatures and other basic ecological components that are used in the food system are not the same everywhere in the world. This is illustrated by the nine agro-ecological zones around the world, as defined by FAO and International Institute for Applied Systems Analysis (IIASA) (see http://www. fao.org/nr/gaez/en). These zones are geographical areas with similar climatic and soil features, determining the natural potential of agricultural production. To what extent these potentials are used relates to economic incentives to using them and governance of such incentives. This again emphasises the connection between biophysical and socio-economic drivers that determine food system outcomes.

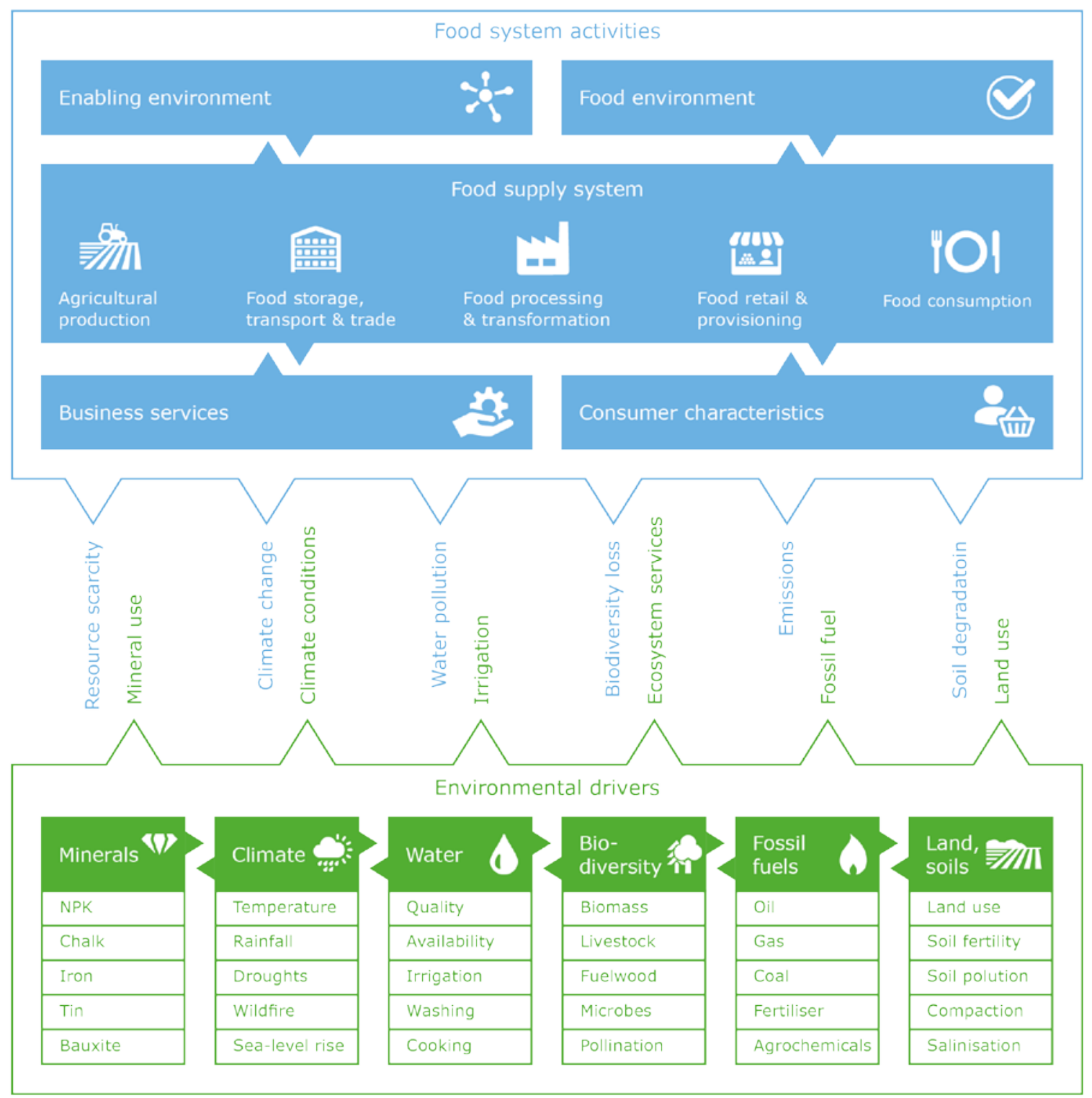

Figure 4 Environmental drivers of the food system 


\subsection{Socio-economic drivers of the food system}

The socio-economic drivers of the food system (shown at the top of Figure 1$)^{5}$ can be divided into five categories (see Figure 5 on the next page). This division into five categories is somewhat arbitrary but it does show concisely and adequately the different aspects that can make up a 'driver' of food systems:

1. Markets: changes in market systems, world prices, trade relations, incomes, profits, wages and labour availability. Markets provide opportunities for matching food supply and demand, but sudden changes in supply, for example, can cause large price fluctuations.

2. Policy: different kinds of policy - for example, on land rights, food security, the environment, labour, trade or food safety - can influence the food system. Policy seeks to guide the outcomes of food system activities in a socially desired direction, but outcomes are sometimes different to what is expected or policy measures do not align with the private interests of actors in the food system.

3. Science $\&$ Technology: research, innovation and education in key areas for agriculture and nutrition, such as chain agreements, transport/logistics and medical or food technology. Research and innovation are important drivers for the productivity growth of all food system activities and can improve the quality and nutritional value of production. Technical or organisational innovations can also contribute to a more sustainable food system.

4. Social organisations: organisational forms or sectors that affect the functioning of the food system, such as households, social movements, media, education and health care. These organisations can help strengthen the position of farmers in the food system, for example, and possibly result in higher incomes.

5. Individual factors: the lifestyle, norms (e.g. animal welfare norms), attitudes and cultures (e.g. halal) that influence the choices of individual actors in the food system. These factors can be place-related and can influence consumer choices. Conversely, the food system can exert influence on individual factors, for example through home delivery of ready-made meals and/or groceries (appealing to a modern lifestyle).

Each of these socio-economic drivers has the potential to influence food system activities but can in turn also be affected by the activities and actors in the system. This can give rise to multiplier effects or feedback mechanisms.

\footnotetext{
5 The main underlying socio-economic trends include demographic development, urbanisation, macroeconomic growth, and cultural and political trends.
} 


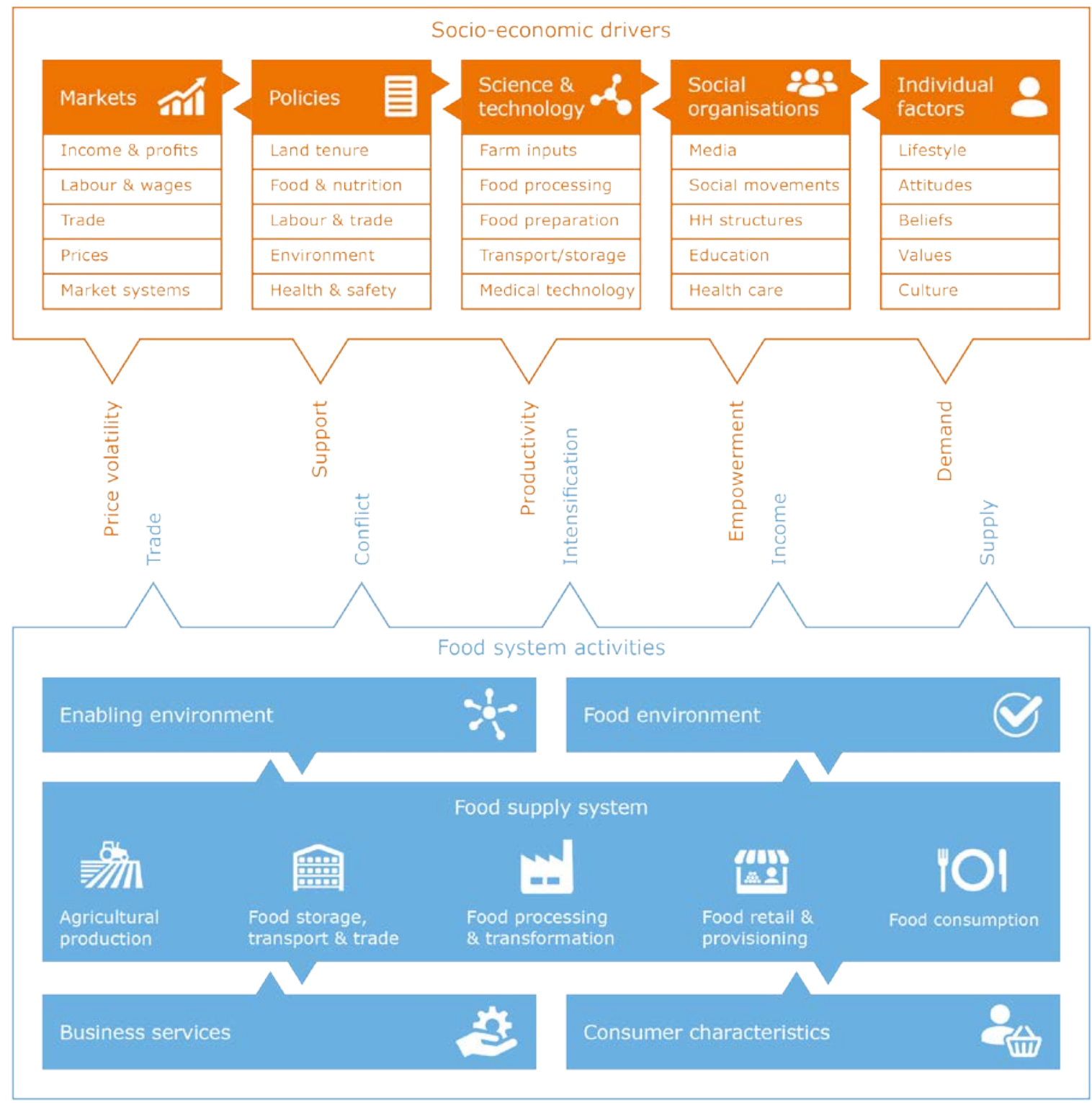

Figure 5 Socio-economic drivers of the food system 


\section{Using the food systems approach to look for sustainable solutions for a sufficient supply of healthy food: examples}

\subsection{Increasing the food supply: more production, less loss and less waste}

Over the coming decades the world's population will grow from the current 7.5 billion to 9 billion people in 2050. The biggest growth will occur in developing countries. In a business-as-usual scenario, this means that global food production will have to increase by $60 \%$ in order to feed the world's growing population in 2050 (UN, 2015).

In order to meet this enormous challenge, most strategies focus on expanding production capacity and productivity in developing countries, for example by improving services to farmers through training and access to inputs such as credit. Thus the main focus of these conventional approaches is to increase primary agricultural production. However, there is a possible trade-off between more intensive production methods and the environment. Alternative ways of boosting food supply without having to take up more of the available natural resources, with a possible negative environmental impact, can be sought by intervening elsewhere in the food chain.

Studies show that $30 \%$ of the food produced in the value chain is lost, either through loss in the production chain (especially in poor countries) or because it is wasted by the consumer (more so in rich countries than in poorer ones) (for an overview, see: WWF, 2016). This means that food availability can be increased by ensuring that a larger portion of primary agricultural production reaches and is used by the consumer.

One way to do this is to improve post-harvest management: the storage, processing and transport of food products in the chain. If products are refrigerated or processed, for example, they will keep for longer, while better roads facilitate the transport to market (e.g. cities). Thus entry points for interventions and investments are found mainly in the transport and processing stage of the chain respectively, and with the government and government policy to ensure an effective infrastructure. Another possibility is to increase consumer awareness of their purchasing and consumption behaviour in order to tackle waste. Addressing the issue of waste can be supported by providing information about what people need in terms of nutrition (dietary guidelines), or by alerting consumers to the environmental impact of food-wasting behaviour. Figure 6 on the next page presents some of these interventions within the food system diagram as outlined in Section 4. The arrows in Figure 6 show the interactions between socio-economic and/or environmental factors and the food system activities. The red arrows from the socio-economic part to the food production system indicate feedback from an earlier change in activities in the food production system (feedback loop), while the green arrows do the same for feedback from the environmental part of the system. The figure shows that there is more than one option for reducing losses/waste. Policy programmes should ensure that the proposed interventions are the most effective and efficient, given the local situation.

There is a possible trade-off between reducing losses and/or waste and environmental or socioeconomic consequences. The reduction of losses/waste ensures a greater supply of food, which can lead to a drop in prices. While this benefits consumers, it means less income for farmers (producers). Falling incomes can tempt farmers to increase their use of land, fertiliser and/or water in an attempt to nevertheless generate an adequate income through higher production. This can have a negative impact on the environment, but prices may also fall further (because of even greater market supply), with an associated drop in farmers' incomes. A possible solution is to switch to products with more 
added value in order to increase returns per unit of produced product. Another option is to encourage producers to be more efficient in their use of available land and other inputs, for example through better recycling of minerals from animal manure and by using by-products or food remains in animal feed and compost (focus on circular processes). This can reduce the costs per unit of product while making the production method more sustainable. Feedback loops of this kind, from the market and the ecosystem based on measures relating to post-harvest management and/or waste reduction, can be thought through using the FSA.

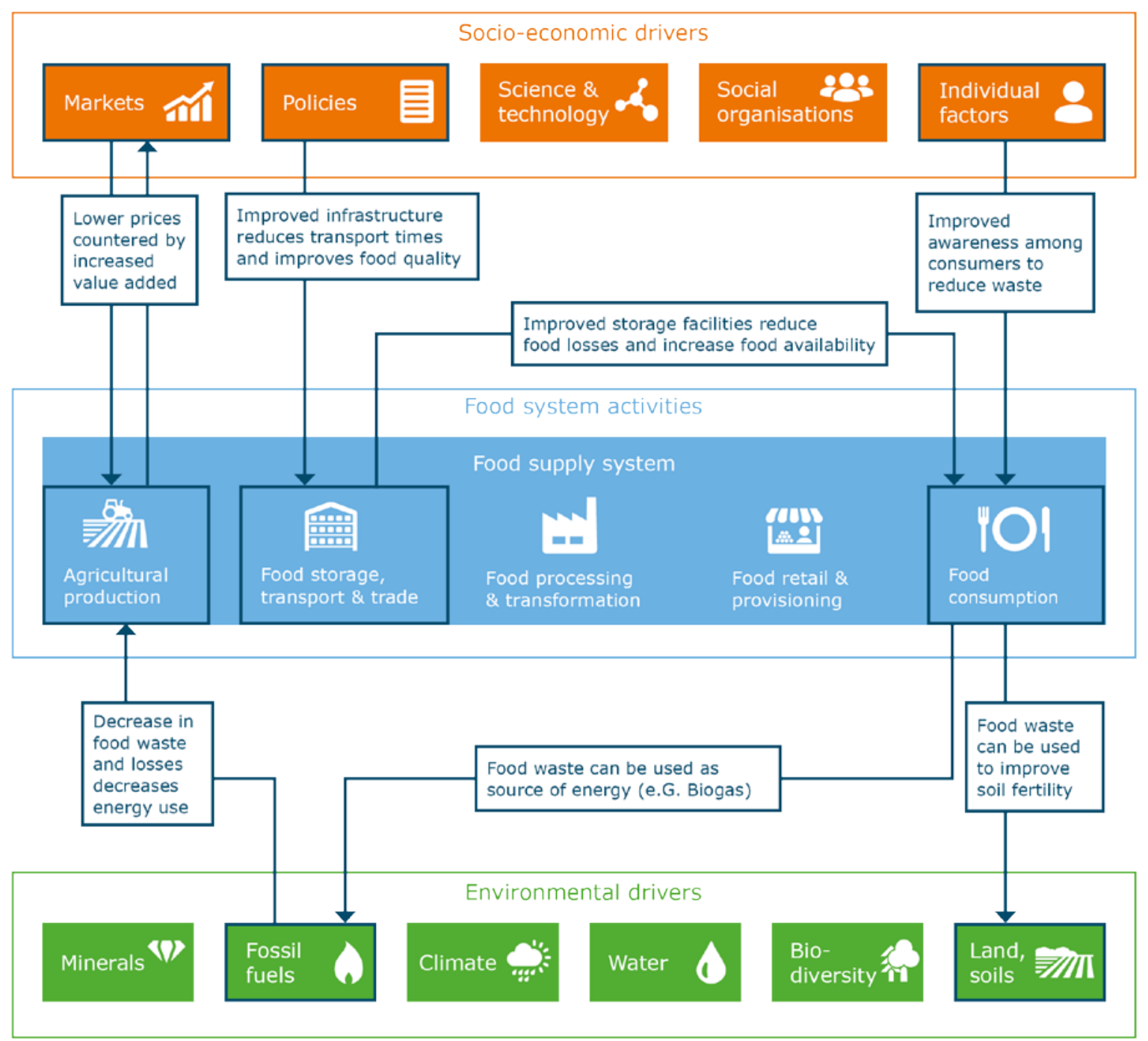

Figure 6 Food systems thinking around production, post-harvest and waste

\subsection{Malnutrition: influencing consumer behaviour and the production of healthy food}

Malnutrition is a central theme in food systems thinking. In total 2 billion people suffer from a shortage of micronutrients. This occurs mainly, although not exclusively, in the least developed countries (World Bank, 2016). Contributing to a more varied diet with the right micronutrients is a major challenge for the food system of the future.

Hunger and malnutrition are manifested at the level of the consumer and are determined among other things by income, prices and access to food. An important external factor in the consumption pattern is the food environment, i.e. the physical and social environment that affects what people eat. This 
plays a particularly significant role in urban areas. 'Environmental factors' refers to the extent to which consumption is 'driven' by advertising or the information provided via labels or quality seals, as well as the physical organisation of the environment, such as the proximity of fast food restaurants. Aspects such as knowledge, time, purchasing power and personal preferences for certain foods can also influence consumer choices.

Influencing these external factors can play a key role in combating malnutrition. A good example of policy that targets the food environment are the 'food for education' programmes, which increase the availability of healthy, diverse food in schools, thereby contributing to an improved micronutrient status among growing children (Adelman et al., 2008). Other programmes strengthen the position of women, both in food production and in terms of their role as consumers and carers for their families. ReSAKKS (2015) gives a range of examples of how women's empowerment can help reduce malnutrition. Figure 7 presents some of these examples by indicating where the interventions are made in the food system and which socio-economic and environmental factors can be involved as drivers.

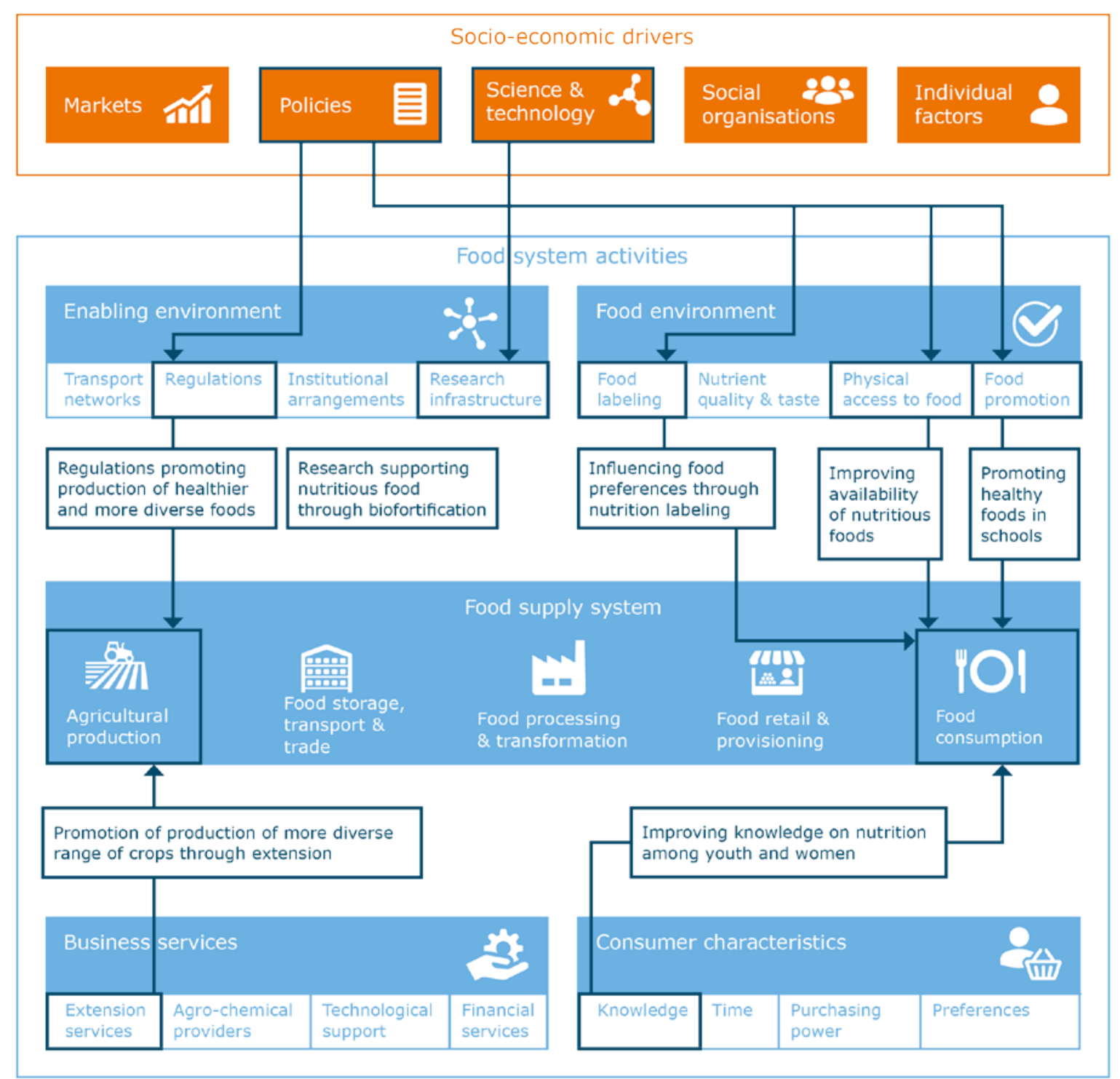

Figure 7 Food systems thinking around healthy food

The food system serves first and foremost to produce healthy food. The Global Panel (2016: 99-107) emphasises the importance of policy aimed at improving food safety and quality, and suggests a series of measures that actors in all segments of the food system can deploy in order to produce healthier 
foods (including fruit, vegetables, legumes, poultry) in greater quantities. Policy can also focus on encouraging diversity of agricultural production or the biofortification of staple crops; the former will mainly target farmers and the latter mainly the processing industry (Covic and Hendriks, 2016; Nestel et al., 2006). In both cases chains need to be organised efficiently so that more nutritious products can be offered to consumers at affordable prices. The public role could involve contributing to a sound infrastructure for the production, storage and transport of nutritious food. Policy could also target information for consumers (e.g. drawing up dietary guidelines or imposing requirements on product labelling and advertising) to encourage them to eat healthier foods. Imposing a tax on fatty and/or sweet products is a further incentive for change. ${ }^{6}$

\subsection{Climate change: feedback involving food system activities}

Climate change will ultimately be a decisive factor in the future security of our food. Research shows that the food system is responsible for $19-29 \%$ of anthropogenic greenhouse gas emissions.

Agricultural production, including indirect effects through changes in land use, accounts for the bulk of this: $80-86 \%$. Conversely, the food system is largely dependent on climate conditions. Studies show that climate change will have a significant impact on food production, trade flows, food prices and farmer incomes, with parts of the globe possibly becoming unsuitable for agricultural production if there is a rise in global average temperature (Vermeulen et al., 2012; OESO, 2015).

Feedback mechanisms between production activities and impacts on natural conditions (e.g. greenhouse gas emissions or erosion) and on resources (such as soil, water) are vital when analysing the relationship between the food system and the environment, but they are also complicated and difficult to decipher. Many forms of agriculture involve greenhouse gas emissions, but the relationships differ for plant and animal production in terms of cause-effect pathways, intensity and the natural resources involved. Climate changes resulting from these emissions are in turn reflected in the workings of the food system. Climate changes lead to higher temperatures, greater extremes and more frequent drought, and in certain areas more rain.

To illustrate the relationships and possible intervention pathways in a way that can be clearly understood, we have confined ourselves in Figure 8 (see below) to showing interventions aimed at changes in agricultural production designed to remain within the environmental limits of the system.

There are different methods for coming to grips with the feedback mechanisms that play such a key role in the interaction between the food production system and the climate. One of the ways to reduce the impact of agricultural activities on the environment (mitigation) is the sustainable intensification of agriculture (Tilman et al., 2011; Montpellier Panel, 2013). Encouraging higher productivity on a smaller area of land can prevent the additional greenhouse gas emissions that would result from expanding the agricultural area. However, emissions per unit of output can still increase, partly due to the growing dependence on fossil fuels that agricultural intensification can entail (WWF, 2016). The way in which this higher production per hectare is achieved therefore needs to be climate-smart. This can be done, for example, by applying smarter methods of crop rotation, or by using precision agriculture to better match the application of inputs (such as water and artificial fertiliser) to the local natural soil or temperature conditions (see www.ag4impact.org for practical applications in Africa). Adaptation measures can in turn cushion climate impacts, for example, by using better water management or drought-resistant seeds to also enable sufficient production under drier conditions or by switching to other crops (Branca et al., 2011). Investments in better weather forecasting can also make a major contribution to farmer resilience to changing climate conditions (FAO, 2013). The choice of technical solution should always be made in the light of socio-economic conditions and possibilities. The question is: how can the measure most efficiently achieve the biggest possible impact (a trade-off

\footnotetext{
6 Mexico (where $70 \%$ of people are overweight) introduced a sugar tax in 2014 . More than $70 \%$ of added sugars in the diet come from soft drinks. After two years the tax led to a $10 \%$ reduction in soft drink sales and to greater water consumption. The health effects are not yet measurable (The Guardian, 22 February 2017,

https://www.theguardian.com/society/2017/feb/22/mexico-sugar-tax-lower-consumption-second-year-running.
} 
between financial costs and earnings)? This points once again to the contribution that systems thinking can make in terms of effective, sustainable solutions and in the societal consideration of trade-offs (governance, financial aspects).

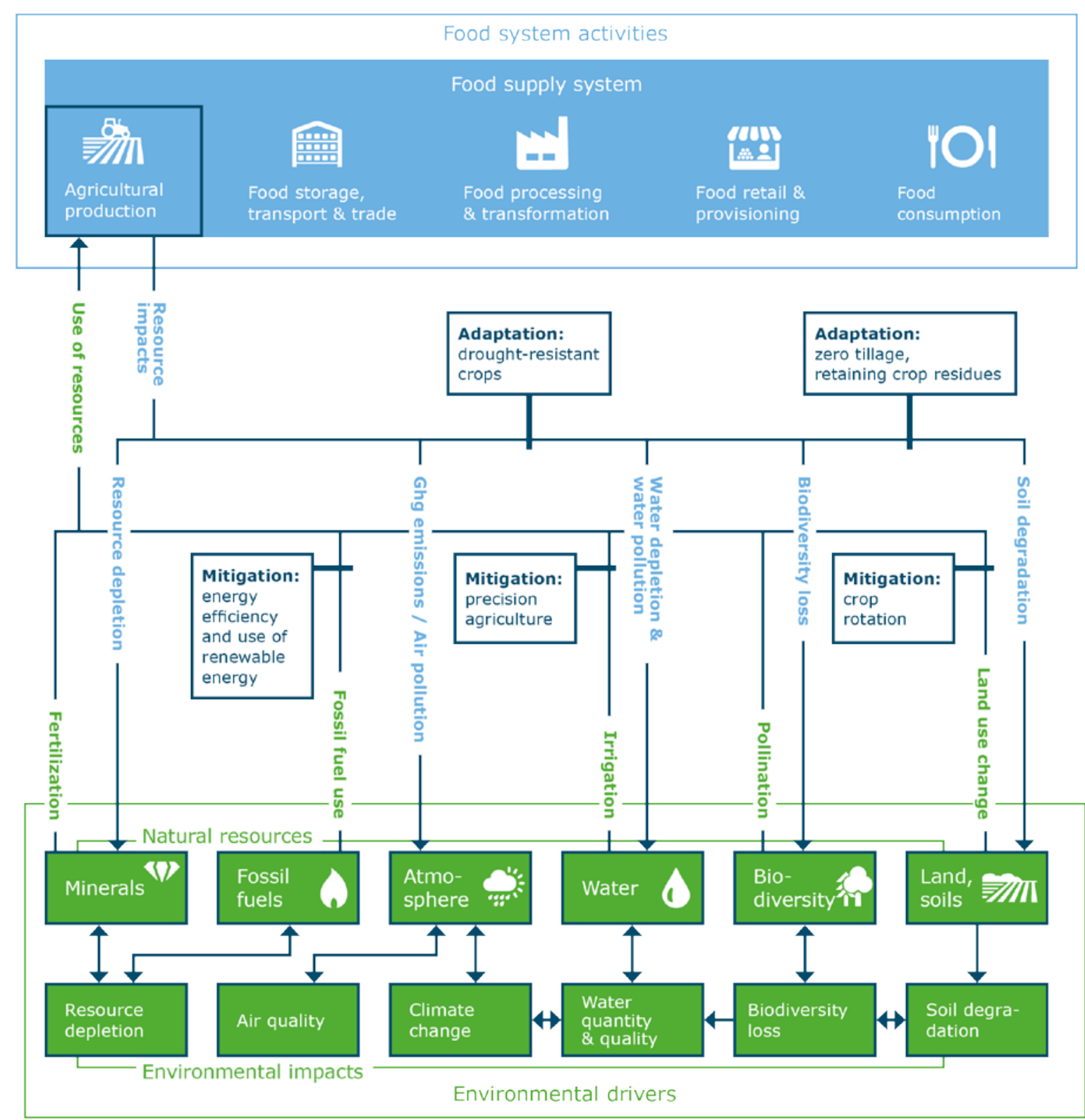

Figure 8 Food systems thinking around climate change: the sustainable intensification of agricultural production

Alongside agricultural production, there are of course other activities in the food production chain that have an environmental impact. Storage, transport, processing and retail also consume considerable energy, thereby contributing to greenhouse gas emissions. Energy saving, the recycling of food remains as biogas or using less packaging material are a few options for reducing the environmental harm of these activities. New technology to save energy or create biodegradable packaging materials can be enforced by means of environmental and other legislation and by regulation, and/or through economic incentives (taxes and subsidies). Also, a dietary change from meat to plant products can make a major contribution to reducing the food system's greenhouse gas emissions: looking at an American diet, the production of plant-based beef substitutes would produce only $4 \%$ of the greenhouse gas associated with the production of beef (Eshel et al., 2016; see Springman et al., 2016 for examples from other parts of the world). 


\subsection{Poverty and productivity: escaping the poverty trap}

Half of the world's working population works in the agricultural sector. At present the food system fails to provide most of them with an adequate income, and $75 \%$ of all farmers live in poverty (New Foresight, 2017). Poverty is the biggest threat for producers worldwide and the main cause of food insecurity (WWF, 2016).

In particular, it is farmers producing on a small scale who tend to be caught up in a negative spiral known as the poverty trap. Because their livelihood depends on a small patch of land, they have difficulty making ends meet. To earn more, they need to increase productivity. To increase productivity, they have to make certain investments, and in order to make those investments, they need access to financial resources. But because their plot of land is so small, and they often have no official land rights, financial institutions do not view them as creditworthy and they may find it very difficult to obtain a loan. As a result, they are often unable to invest in productivity growth.

Changes in the socio-economic context can help to break through the poverty trap, for example by facilitating market access for farmers. An example is a contract farming arrangement, in which a farmer guarantees supply to the buyer, who in return helps the farmer with inputs that he or she can use to increase productivity or improve product quality (Ton et al., 2017). The government can also do a great deal to expand economic opportunities for farmers. Investments in infrastructure, such as good roads, as well as digital and social networks (including farmer organisations), bear a strong relationship to food security because they increase the farmer's access to the market (Blimpo et al., 2012). Finally, access to financial services is essential for farmers wanting to escape the poverty trap. Micro-credit programmes contribute to higher and more stable incomes for farmers, which translates into better nutrition and health for their families (Littlefield et al., 2003). In these examples the agricultural production system is closely linked to socio-economic drivers (institutional structures such as contracts or farmer organisations).

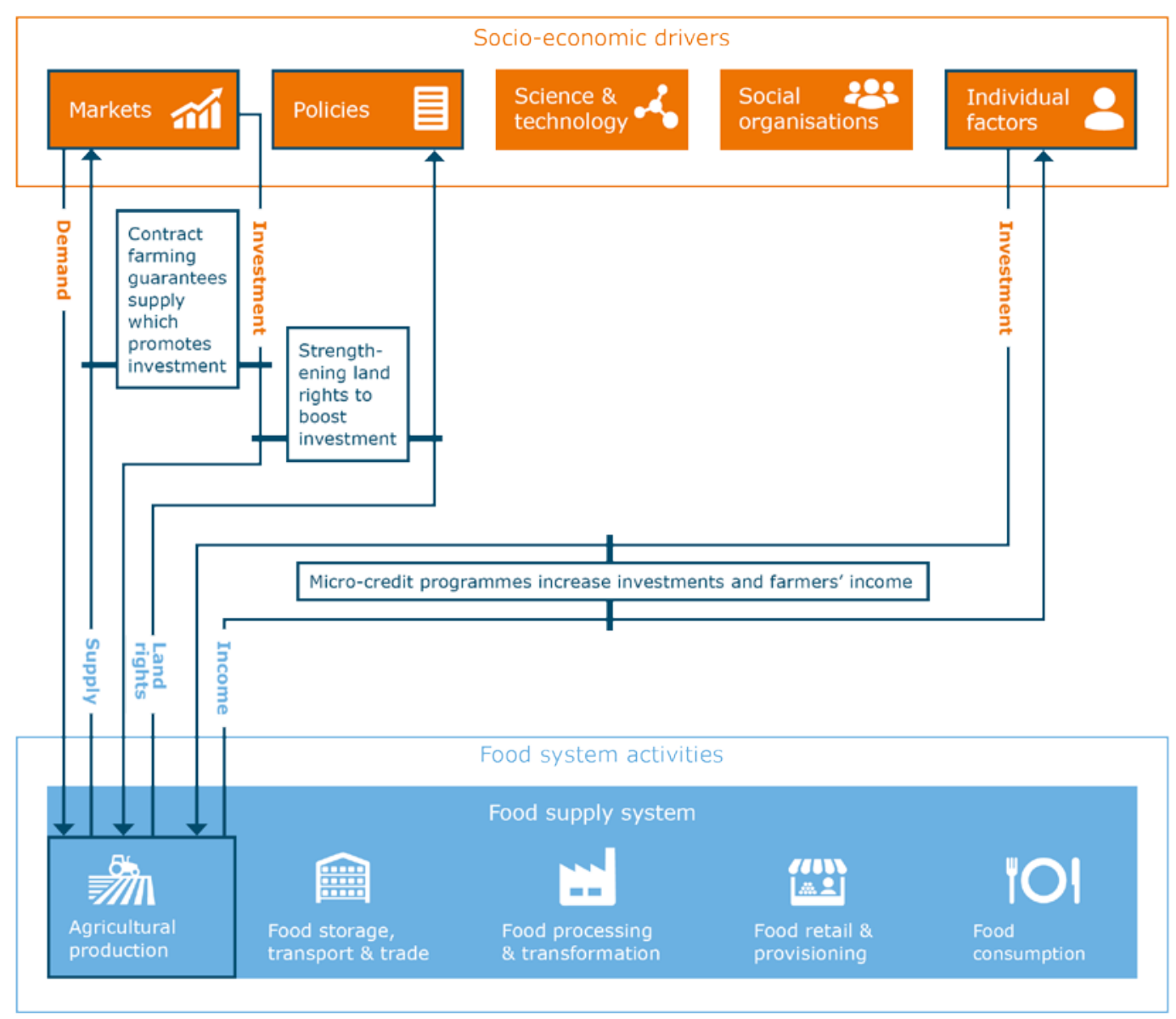

Figure 9 Food systems thinking around poverty and productivity 


\section{Conclusion: how does the food systems approach help us?}

\subsection{From activities to outcomes}

Despite the big increase in world food production, there are still more than 800 million people who are chronically malnourished (FAO, 2017a). Added to that, this growth in production has been accompanied by growing pressure on the environment. A food systems approach can help find solutions that will provide the world's growing population with a sufficient supply of healthy food within the environmental limits. It finds solutions by intervening in parts of the system (and where necessary outside the system) other than where the problem occurs.

The notion of 'access' has been at the centre of debates about food security since the mid-1990s (FAO, 1996; Ingram, 2011). It is no longer simply about the availability of food, but also about affordability and the preferences (often driven by policy or other incentives) that influence people's access to that food. This has shifted the focus from activities within the food production system (production, transport, processing) to the outcomes of those activities in the form of the consumption, access and availability of food (all elements of 'food security'). Because access to affordable, healthy and diverse food depends not only on production but also on factors outside the food production system, a broader approach is required when analysing the impact of interventions aimed at enhancing food security. The conceptual framework of the food system is ideal for this purpose.

This shift in focus from production chain activities to their outcomes can also be seen in the increasing attention to sustainability and climate resilience (and adaptability) with regard to food system activities. The food systems approach helps us to look further than production activities alone in that it also documents the environmental impacts and socio-economic outcomes of the food system.

Conversely, interventions in the food system's socio-economic or biophysical context can also influence the agent response within the system by influencing the behaviour of actors within that system through changes in the system context. Examples include stimulating the demand for healthy food and encouraging producers to invest in more sustainable production methods. With respect to promoting demand for healthier food, the Global Panel (2016) says that governments, in collaboration of course with the private sector and civil society (including NGOs), can directly and indirectly encourage the consumption of healthy food through subsidies, taxes, dietary guidelines, labelling, information, research and other measures.

\subsection{Interdependence}

The food systems approach highlights the interdependent nature of global challenges in the agrosector. It shows how production systems, consumer behaviour, food security, climate change, natural conditions (i.e. the available natural resources) and socio-economic trends interact with one another. It prevents people from becoming mired in silo thinking, whereby possibilities for enhancing food security are sought within a single subsystem without taking into account the effects of an intervention on other parts of the system, thereby overlooking possible trade-offs.

By mapping out the interactions between different subsystems, food systems thinking can contribute to an integrated approach that makes smart use of solutions at other levels of scale. By looking at how different subsystems complement one another, optimum use can be made of existing feedback mechanisms and multiplier effects. That has proved useful, for example, in identifying opportunities to promote climate-smart agricultural methods, such as by making vital inputs (seeds, credit, training) available, improving water management or adapting grazing methods. In addition, climate risks for 
agricultural production can be limited by taking measures outside the food system, such as reforestation programmes or further tightening the rules for carbon credits trading.

\subsection{Tipping points}

The food systems approach highlights the complexity of the food system and how different subsystems interact with one another. It also reveals the non-linear nature of many cause-effect pathways. This means that once a tipping point is reached, an increase in one variable can sometimes lead to a disproportionally large increase in another. An example of this is climate change, whereby anthropogenic greenhouse gas emissions can bring about irreversible changes in our climate system. Because the food systems approach looks in detail at interactions between different systems, it is essential that it be used to study this kind of tipping point, which occurs outside the food system but which will have a direct impact on food system outcomes. However, the balance within the food system can also be disrupted by internal processes such as specialisation and monoculture, with their attendant risks of animal and plant diseases. The food system is highly vulnerable as a result of a onesided emphasis on expanding food production, without taking sufficient account of changes in the natural, technical and social systems surrounding it. Thus much of the recent literature about the relationship between food security and food systems emphasises the need for the food system to be not only sustainable but also resilient enough to cope with threats and uncertainties (often in relation to climate change) (Global Panel, 2016; WWF, 2016; UN, 2016; HLPE, 2017): concepts like 'adaptability' and 'transformability' play a key role in enhancing the resilience of the food system. Resilience thinking is a form of systems thinking that embraces the need to change in order to survive (Ge et al., 2017; Tendall et al., 2015). Sustainable solutions for a sufficient supply of healthy food requires changes in the food system, such as more efficient use of natural resources and less waste. Adaptations that enhance the system's resilience to external shocks (see also Section 2.1) may be of a technical, organisational, political policy or socio-economic nature. Weighing up options for solutions to make the food system more resilient to disruptions calls for intensive collaboration between a range of research disciplines, policymakers and other stakeholders.

\subsection{Action perspective: prioritising interventions using problem analyses based on a food systems approach}

The food systems approach helps to reveal the underlying structures of and relationships within the food system. Cause-effect patterns are enriched by feedback from other parts of the system that might otherwise be overlooked in the absence of a systematic approach. These insights help us to formulate the right entry points for policy. They can also generate an awareness that, alongside public interventions, the private sector itself can make a significant contribution to improving food system outcomes. Complementary efforts from the sector itself can safeguard both the minimum scale of interventions (societal) and the necessary return on investments (private economic).

Certain unsatisfactory system outcomes (such as poverty, malnutrition, lack of training) can often be traced back to a number of root causes. Root causes are often location-specific. It is therefore important to properly analyse the origins of poverty, hunger and/or malnutrition (i.e. what the precise limiting factors are) in the region/country in question, and to identify which parts of the food system are responsible for the problem and what options there are for policy interventions. When prioritising policy options, it is essential to find out how interventions will contribute to food system sustainability, i.e. the long-term feasibility of the system in social, economic and environmental/climatological terms. The food systems approach increases the prospects of both problem analysis and the search for ways of improving food system outcomes. In this way, food systems thinking helps to prioritise the different intervention pathways.

The food systems approach offers not only a means to compare different intervention possibilities but also a framework for systematically analysing the synergies and trade-offs between different policy objectives. Of course it must be said that the most recent literature in this field also recognises that 
the complexity of the food system makes it extremely difficult to precisely pinpoint the relationships and feedback mechanism between the different parts of the system (and with other systems) and to say what will work in order to improve system outcomes. Nevertheless, the framework does have a number of advantages (see also Ingram, 2011). First, it provides a checklist for the topics that should in any event be addressed in order to improve food security, certainly in relation to other policy objectives, and it identifies the actors and other parties who should be involved. Second, it helps to document the impact of environmental and climate changes on food security by pointing out different vulnerabilities in the food system. In that sense the concept can help in the search for ways of enhancing the system's resilience to climate change. Third, it helps to determine the most limiting factors when it comes to achieving food security, and thereby to identify effective interventions aimed at improving food security. These advantages make it worthwhile to adopt a food systems approach within Dutch policy aimed at contributing to sustainable solutions for a sufficient supply of healthy food in the world. 


\section{References and websites}

Adelman, S., D. Gilligan and K. Lehrer (2008). How Effective are Food for Education Programs? A Critical Assessment of the Evidence from Developing countries. Food Policy Review 9. Washington: IFPRI.

Blimpo, M., R. Harding and L. Wantchekon (2012). Public Investment in Rural Infrastructure: Some Political Economy Considerations.

Boulding, K. (1956). "General Systems Theory: The Skeleton of Science" In: Management Science, 2, 3 (Apr. 1956) pp.197-208. Reprinted in: General Systems, Yearbook of the Society for General Systems Research, vol. 1, 1956.

Branca, G., N. McCarthy, L. Lipper and M.C. Jolejole (2011). Climate Smart Agriculture: A Synthesis of Empirical Evidence of Food Security and Mitigation Benefits from Improved Cropland Management

Covic, N. and S.L. Hendriks, ed. (2016). Achieving a nutrition revolution for Africa: The road to healthier diets and optimal nutrition. IFPRI, ReSAKSS annual trends and outlook report

Ericksen, P.J. (2007). Conceptualizing food systems for global environmental change research. Global Environmental Change. doi: 10.1016/j.gloenvcha.2007.09.002

Eshel, G., A. Shepon, E. Noor and R. Milo (2016). Environmentally optimal, nutritionally aware beef replacement plant based diets. Environmental Science and Technology, 2016, 50, 8164-8168. DOI : 10.1021 /acs.est. 6 b01006

FAO (1996). Rome declaration and world food summit plan of action. Rome: FAO.

FAO (2013) Climate-Smart Agriculture Sourcebook. Food and Agriculture Organization: Rome.

FAO (2013). Edible insects. Future prospects for food and feed security. Food and Agriculture Organization of the United Nations (Vol. 171).

FAO (2017a). The State of Food Security and Nutrition in the World 2017. Rome, FAO

FAO (2017b). Ending poverty and hunger by investing in agriculture and rural areas. Rome, FAO. http://www.fao.org/3/a-i7556e.pdf

Folke, C., S. R. Carpenter, B. Walker, M. Scheffer, T. Chapin, and J. Rockström. 2010. Resilience thinking: integrating resilience, adaptability and transformability. Ecology and Society 15(4): 20. [online] URL: http://www.ecologyandsociety.org/vol15/iss4/art20/

Fresco, L.O., R. Ruben and M. Herens (2017). Challenges and perspectives for supporting sustainable and inclusive food systems. Great Insights, September/October 201713-15.

Ge, L., N.P.R. Anten, I.D.E. van Dixhoorn, P.H. Feindt, K. Kramer, R. Leemans, M.P.M. Meuwissen, H. Spoolder and W. Sukkel. 'Why we need resilience thinking to meet societal challenges in biobased production systems.' Current Opinion in Environmental Sustainability 2016, 23:17-27. http://dx.doi.org/10.1016/j.cosust.2016.11.009

Global Panel on Agriculture and Food Systems for Nutrition (2016). Food systems and diets: Facing the challenges of the 21st century. London, UK. 
HLPE (2014). Food losses and waste in the context of sustainable food systems. A report by the High Level of Experts on Food Security and Nutrition of the Committee on World Food Security. Rome.

HLPE (2017). Nutrition and food systems. A report by the High Level of Experts on Food Security and Nutrition of the Committee on World Food Security. Rome.

Ingram J.S.I. (2011). A food systems approach to researching food security and its interactions with global environmental change. Food Security, 3: 417-431. DOI: 10.1007/s12571-011-0149-9.

Ingram, J.S.I. and M. Brklacich (2002). Global Environmental Change and Food Systems (GECAFS). A new, interdisciplinary research project. Die Erde, 113, 427-435.

Kamerbrief over Nederlandse inzet voor wereldwijd voedselzekerheid. 18 November 2014. Minister van Buitenlandse Zaken en Ontwikkelingssamenwerking, Staatsecretaris voor Economische Zaken. Referentie:DME-2014.601068

Littlefield, E., J. Murduch and S. Hashemi (2003). Is Microfinance an effective strategy to reach the millennium development goals?

Lobell, D.B., M.B. Burke, C. Tebaldi, M.D. Mastrandrea, W.P. Falcon and R.L. Naylor (2008). Prioritizing climate change adaptation needs for food security in 2030. Science, 319(5863).

Maxwell, S., and R. Slater (2003). Food policy old and new. Development Policy Review, 21(5-6), 531-553.

The Montpellier Panel (2013). 'Sustainable Intensification: A New Paradigm for African Agriculture'. The Montpellier Panel Report 2013. London: Imperial College.

http://www3.imperial. ac. uk/africanagriculturaldevelopment/themontpellierpanel/themontpellierpa nelreport2013.

New Foresight \& Commonland (2017). New Horizons for the Transitioning of our Food System: Connecting Ecosystems, Value Chains and Consumers.

Nestel, P., Howarth E. Bouis, J.V. Meenakshi, and Wolfgang Pfeiffer (2006). Biofortification of Staple Food Crops: Six Questions, IFPRI

OECD (2015). The Economic Consequences of Climate Change. Available on: http://dx.doi.org/10.1787/9789264235410-en

Shepon, A., G. Eshel, E. Noor and R. Milo (2016). Energy and protein feed-to-food conversion efficiencies in the US and potential food security gains from dietary changes. Environmental Research Letters 11. doi: 10.1088/1748-9326/11/10/105002

Springmann, M., H.J.C. Godfray, M. Rayner and P. Scarborough (2016). Analysis and valuation of the health and climate change co-benefits of dietary change. Proc. Natl Acad. Sci. 113 4146-51. www.pnas.org/cgi/doi/10.1073/pnas. 1523119113

Tendall, D. M. J. Joerin, B. Kopainsky, P. Edwards, A. Shreck, Q.B. Le, P. Kruetli, M. Grant and J. Six (2015). Food system resilience: Defining the concept. Global Food Security 6 (2015), 17-23

UNEP (2016) Food Systems and Natural Resources. A Report of the Working Group on Food Systems of the International Resource Panel. Westhoek, H, Ingram J., Van Berkum, S., Özay, L., and Hajer M.

United Nations (2015). Zero Hunger Challenge. Pathways to zero hunger: Transforming our Food Systems to Transform our World. Rome: Committee on World Food Security.

United Nations (2015). World Population Prospects 2015. 
Urruty, N., D. Tailliez-Lefebvre and C. Huyghe (2016). Stability, robustness, vulnerability and resilience of agricultural systems. A review. Agron Sustain Dev 2016, 36:1-15.

Vermeulen, S.J., P.K. Aggarwal, A. Ainslie, C. Angelone, B.M. Campbell, A.J. Challinor, J.W. Hansen, J.S.I. Ingram, A. Jarvis, P. Kristjanson, C. Lau, G.C. Nelson, P.K. Thornton and E. Wollenberg (2012). Options for support to agriculture and food security under climate change. Environmental Science and Policy 15: 136-144.

Wheeler, T. and J. von Braun (2013). 'Climate Change Impacts on Global Food Security'. In: Science, vol 341, 2 August.

World Bank (2016). Shaping the Global Food System to Deliver Improved Nutrition and Health.

WWF (2016). The Global Food System: An Analysis. WWF Netherlands \& Metabolic Lab. 
Wageningen Economic Research P.O. Box 29703

2502 LS The Hague

The Netherlands

T +31 (0)70 3358330

E communications.ssg@wur.nl

www.wur.eu/economic-research

Wageningen Economic Research MEMORANDUM

2018-064
The mission of Wageningen University \& Research is "To explore the potential of nature to improve the quality of life". Under the banner Wageningen University \& Research, Wageningen University and the specialised research institutes of the Wageningen Research Foundation have joined forces in contributing to finding solutions to important questions in the domain of healthy food and living environment. With its roughly 30 branches, 5, 000 employees and 10,000 students, Wageningen University \& Research is one of the leading organisations in its domain. The unique Wageningen approach lies in its integrated approach to issues and the collaboration between different disciplines. 



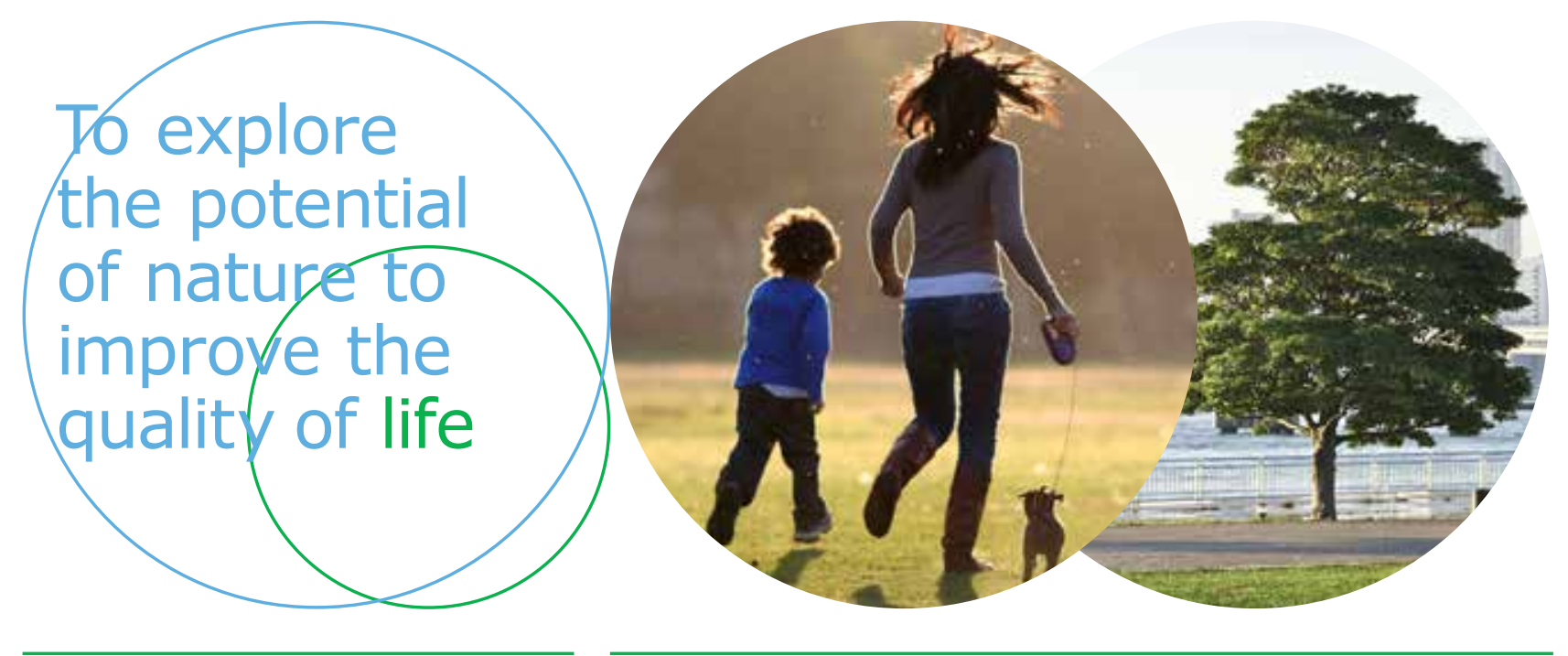

Wageningen Economic Research P.O. Box 29703

2502 LS Den Haag

The Netherlands

E communications.ssg@wur.nl

www.wur.eu/economic-research

Memorandum 2018-064
The mission of Wageningen University \& Research is "To explore the potential of nature to improve the quality of life". Under the banner Wageningen University \& Research, Wageningen University and the specialised research institutes of the Wageningen Research Foundation have joined forces in contributing to finding solutions to important questions in the domain of healthy food and living environment. With its roughly 30 branches, 5,000 employees and 10,000 students, Wageningen University \& Research is one of the leading organisations in its domain. The unique Wageningen approach lies in its integrated approach to issues and the collaboration between different disciplines. 